\title{
Efficacy of Metformin and Chemotherapeutic Agents on the Inhibition of Colony Formation and Shh/Gli1 Pathway: Metformin/ Docetaxel Versus Metformin/5-Fluorouracil
}

\author{
Authors \\ Maryam Fatehi-Agdam¹, 2, Mohammad Amin Vatankhah1, 2, Reza Panahizadeh1, 2D, Farhad Jeddi2, \\ Nowruz Najafzadeh2 ${ }^{\text {(D) }}$
}

Affiliations

1 Students Research Committee, School of Medicine, Ardabil University of Medical Sciences, Ardabil

2 Research Laboratory for Embryology and Stem Cells, Department of Anatomical Sciences, School of Medicine, Ardabil University of Medical Sciences, Ardabil

\section{Key words}

metformin, docetaxel, 5-fluorouracil, Shh, Gli1, Gli2, gastric cancer

\author{
received 22.07.2020 \\ accepted 24.08.2020 \\ published online $\quad 28.09 .2020$ \\ Bibliography \\ Drug Res 2021; 71: 17-25 \\ DOI 10.1055/a-1248-9008 \\ ISSN 2194-9379 \\ (C) 2020. Thieme. All rights reserved. \\ Georg Thieme Verlag KG, Rüdigerstraße 14, \\ 70469 Stuttgart, Germany

\section{Correspondence} \\ Nowruz Najafzadeh, Ph.D., Associate Professor \\ Research Laboratory for Embryology and Stem Cells, \\ Department of Anatomical Sciences, Ardabil University of \\ Medical Sciences \\ Ardabil 5618985991 \\ Iran \\ Tel.: + 989104075700 \\ nowruz30@gmail.com
}

\begin{abstract}
Background Gastric cancer is a common gastrointestinal cancer characterized by poor prognosis and chemoresistance. Docetaxel and 5-fluorouracil (5-FU) are frequently used for the treatment of gastric cancer. Despite their potent anti-cancer effects, chemoresistance occurs in metastatic gastric cancer. Metformin, a popular anti-diabetic drug, has been proven to have potent anticancer effects on gastrointestinal cancers. Here, we aim to improve this chemotherapy agents' efficacy by pretreatment with metformin.

Methods The AGS gastric cancer cell line were pretreated with three different sub-toxic concentration of metformin and then treated with various concentrations of 5-FU and docetaxel.

The anticancer effects of the combination of metformin with the chemotherapy agents were determined using clonogenic assay and DAPi staining. We used real-time PCR to evaluate Gli1, Gli2, and TWIST1 mRNA expression levels in the gastric cancer cells. Also, the expression of the Shh protein was assessed using immunocytochemistry.

Results Here, we found that metformin sensitized the gastric cancer cells to chemotherapy. The combination treatments were more effective in reducing the number of cancer colonies compared to 5-FU or docetaxel alone. The combination of metformin with 5-FU or docetaxel significantly reduced the number of cells expressing the Shh protein compared to the 5-FU alone or docetaxel alone. Interestingly, we found that the combination of metformin with docetaxel significantly down-regulated the mRNA levels of Gli1, Gli2, and TWIST1 in the AGS gastric cancer cell line compared to docetaxel alone.

Conclusion Overall, our data strongly support an important role for metformin as an enhancer of the efficacy of chemotherapeutic agents against gastric cancer.
\end{abstract}

\section{Introduction}

Gastric cancer is the fifth most common cancer and its mortality rate is high worldwide. The 5 -year survival rate is around $20 \%$ and prognosis remains poor [1]. Gastric cancers are classified in to adenocarcinoma, lymphomas, and mesenchymal tumors. The gastric cancer incidence in countries like Iran, China, Japan, South America, and Eastern Europe is high [2,3]. Gastric cancer is a multi-fac- torial disease and different carcinogens such as Helicobacter pylori infection, cigarette, salt-preserved food, red and high cured meat, alcohol drinking have been reported to contribute to gastric cancer [4]. Surgical resection with immunotherapy and chemotherapy was used to treat metastatic gastric cancer. Several chemotherapy regimens are useful in advanced gastric cancer. Palliative chemotherapy regimens such as ECF (epirubicin, cisplatin, 5-FU), DCF 
(docetaxel, cisplatin, and 5-FU), and ECX (epirubicin, cisplatin, capecitabine) are commonly used to treat metastatic gastric cancer [3].

Docetaxel is widely used against advanced gastric cancer. Docetaxel, a chemotherapy agent, shows anticancer activity against breast, gastric, and ovarian cancers [5]. It binds to free tubulin, stabilizing microtubules, and causes cell cycle arrest at the G2/M stage. Furthermore, docetaxel activates transcription factor AP-1 to induce apoptosis in gastric cancer cells [6]. 5-FU, as a pyrimidine analogue, irreversibly inhibits thymidylate synthase to block DNA synthesis in cancerous cells. It has been used in combination with other cancer drugs to treat breast cancer, head and neck cancers, gastric, colorectal, pancreatic cancers, and squamous cell carcinomas [7]. However, the remarkable toxicity of these drugs limits their use in the clinic.

Due to the side effects of chemotherapy regimens, chemoresistance, and cancer relapse, identifying novel therapeutic agents is a fundamental step in reducing mortality. However, the high toxicity of chemotherapy drugs limits their use in the clinic. Metformin, as an antidiabetic agent, inhibits hepatic gluconeogenesis and reduces postprandial and fasting glucose levels [8]. Also, several studies have been shown that it reduces the incidence of cancer in patients taking this medication for the treatment of diabetes mellitus [9].

Studies have shown that metformin in combination with chemotherapy agents can inhibit the proliferation of gastric cancer cells. It was shown that metformin reduces the growth and proliferation of tumor cells by activation of AMPK and suppression of the mTOR pathway and the HIF1 $\alpha /$ PKM2 pathway [10].

The proliferation of gastric cancer cells is dependent on multiple signaling pathways including sonic hedgehog (Shh) and Notch. Shh signaling plays a critical role in the regulation of drug resistance and gastrointestinal carcinogenesis. In Shh signaling, Shh attaches to its receptor, PATCH1, and activates Smoothened (SMO). Notch signaling involved in epithelial-mesenchymal transition and regulate gastric cancer progression $[11,12]$. Transcription factor Twist is also elevated in gastric cancer cells and promotes tumorigenesis through activation of STAT3 [13].

In gastric cancer, a series of trials have provided evidence that chemotherapy increases survival, but a globally accepted standard chemotherapy and the optimal regimen has not been determined.

Metformin has less toxicity and side effects, and it is a well-tolerated drug. The simultaneous application of metformin with docetaxel or 5-FU might be a more effective treatment, so we decided to evaluate whether sub-toxic doses of metformin could promote the anticancer effects of chemotherapy agents in gastric cancer. Indeed, we examined whether a combination of metformin/docetaxel or metformin/5-FU could change Shh protein expression or Gli1, Gli2, and TWIST mRNA expression levels in the gastric cancer cells.

\section{Materials and Methods}

\section{Drugs and reagents}

Metformin (BP227), docetaxel (01885), and 5-fluorouracil (F6627) were purchased from Sigma-Aldrich. The drugs were dissolved in RPMI at the specified concentrations and stored in a $4^{\circ} \mathrm{C}$ refrigerator.

\section{Cell culture}

The human AGS cell line purchased from the National Cell Bank of Iran (NCBI, Pasteur Institute, Tehran, Iran). The gastric cancer cells were cultivated in RPMI 1640 (Gibco) medium, which was supplemented with $10 \%$ fetal bovine serum (FBS, Gibco) and $100 \mathrm{U} / \mathrm{mL}$ penicillin-streptomycin. The cells were incubated in a humidified atmosphere containing $5 \% \mathrm{CO}_{2}$.

\section{DAPi staining}

Cytotoxicity was determined by the DAPi staining. Briefly, gastric cancer cells $\left(5 \times 10^{3}\right.$ cells/well) were seeded into a 6 -well plate. The cells were treated with subtoxic concentrations (lower than IC $C_{50}$ values) of metformin ( $5 \mathrm{mM})$, docetaxel $(5 \mathrm{nM}), 5-\mathrm{FU}(0.2 \mu \mathrm{g} / \mathrm{ml})$, metformin $(5 \mathrm{mM})+$ docetaxel $(5 \mathrm{nM})$, and metformin $(5 \mathrm{mM})+5-\mathrm{FU}$ $(0.2 \mu \mathrm{g} / \mathrm{ml})$ for $48 \mathrm{~h}$. The subtoxic concentrations were determined according to our recently published results [14]. Then, the cells were fixed with $4 \%$ paraformaldehyde for $30 \mathrm{~min}$. The cells were stained with DAPi $(1 \mu \mathrm{g} / \mathrm{ml})$ for $5 \mathrm{~min}$ and were viewed under an inverted fluorescence microscope (IX 71, OLYMPUS) and images were taken with a digital camera (DP 71, OLYMPUS). Apoptotic cells were identified by the perinuclear condensation of chromatin and the formation of the apoptotic bodies in the nucleus.

\section{Quantification of gene expression by real-time PCR}

Total RNA was extracted using TRIzol reagent (Invitrogen). The RNA concentration was quantified using NanoDrop Spectrophotometer (NanoDrop Technologies, USA).

Complementary DNA (CDNA) synthesis was performed using Viva 2-steps RT-PCR kit (Vivantis, USA). Briefly, all PCR reactions were performed in a total volume of $20 \mu \mathrm{l}$, using $1 \mu$ oligo(dT) primer, and nuclease-free water was mixed with $\mathrm{mRNA}$, incubated at $65^{\circ} \mathrm{C}$ for $5 \mathrm{~min}$ and placed on ice for at least $1 \mathrm{~min}$. Then, $100 \mathrm{u} \mathrm{M-MuLV}$ enzyme and $10 \times$ buffer was added and incubated in $42^{\circ} \mathrm{C}$ for $60 \mathrm{~min}$ and then $85 \mathrm{C}$ for $10 \mathrm{~min}$. Real-time $\mathrm{PCR}$ reaction was performed using the following conditions: $95^{\circ} \mathrm{C}$ for $20 \mathrm{~s}$, followed by 40 cycles of $95^{\circ} \mathrm{C}$ for $5 \mathrm{~s}$, and $60^{\circ} \mathrm{C}$ for $5 \mathrm{~s}$. Primers were designed using OLICO primers analysis software v.7 (Molecular Biology Insights, Inc., DBA Oligo, Inc.).

The primer sequences is listed in $>$ Table 1. We performed quantitative real-time PCR using Power SYBR Green PCR Master Mix (EURx, Ltd, da s, Poland) and a Light Cycler 96 Real-Time PCR System (Roche Applied Science). Fold changes were calculated using the comparative $\mathrm{Ct}$ method. The relative amount of the targeted gene's transcripts was normalized by the amount of GAPDH transcript in the same cDNA [15].

\section{Clonogenic assay}

The AGS gastric cancer cells were seeded into 6-well plates at a density of 500 cells/well and incubated overnight. The cells were treated with various concentrations of metformin $(0.6-10 \mathrm{mM}), 5-\mathrm{FU}$ $(0.45-6 \mathrm{ng} / \mathrm{ml})$, docetaxel $(0.3-5 \mathrm{pM})$, metformin $(1.25 \mathrm{mM})+$ docetaxel (0.3-5 pM), metformin (2.5 mM) + docetaxel (0.3-5 pM), metformin $(1.25 \mathrm{mM})+5-\mathrm{FU}(0.45-6 \mathrm{ng} / \mathrm{ml})$, and metformin $(2.5 \mathrm{mM})$ +5 -FU $(0.45-6 \mathrm{ng} / \mathrm{ml})$ and incubated for 10 days to form colonies. The medium was removed and the cells were fixed with $4 \%$ paraformaldehyde (PFA). Then, the colonies were stained with crystal violet solution $(0.21 \%$ crystal violet, $1 \%$ methanol) and the number of colonies was counted using a microscope. 


\section{Immunocytochemistry}

Briefly, the cells were grown on 6-well plates and were treat with 5-FU $(0.0005$ and $0.003 \mu \mathrm{g} / \mathrm{ml})$, docetaxel $(0.005$ and $0.025 \mathrm{nM})$, metformin $(20 \mathrm{mM})+5-\mathrm{FU}(0.0005 \mu \mathrm{g} / \mathrm{ml})$, metformin $(20 \mathrm{mM})+5-\mathrm{FU}$ $(0.003 \mu \mathrm{g} / \mathrm{ml})$, metformin $(20 \mathrm{mM})+$ docetaxel $(0.005 \mathrm{nM})$, and metformin $(20 \mathrm{mM})+$ docetaxel $(0.025 \mathrm{nM})$. After $48 \mathrm{~h}$, the cells were carefully washed with PBS for three times. The cancer cells were fixed in $4 \% \mathrm{PFA}$ ( $\mathrm{pH} 7.4$ ) for $15 \mathrm{~min}$ at room temperature and washed with PBS. Then, the cells were incubated in blocking buffer for $30 \mathrm{~min}$.
Cells were incubated with the primary Shh antibody (sc-365112) overnight at $4{ }^{\circ} \mathrm{C}$. Then, the cells were incubated in the dark with a secondary antibody (Alexa Fluor 488) for $2 \mathrm{~h}$ at room temperature. Finally, the cells were observed by a fluorescence microscope.

\section{Statistical analysis}

The tests were repeated three times in this study. All data were analyzed using SPSS V.21 software (SPSS Inc., USA). The significant differences were determined using Student's t-test and one-way ANOVA followed by the Tukey post hoc comparison test $(\mathrm{P}<0.05)$.

- Table 1 List of primer sequences used for RT-PCR analysis.

\begin{tabular}{|l|l|l|c|}
\hline & Forward & Reverse & Product size \\
\hline Gli1 & CCAACTCCACAGGCATACA & CGGCAGTCAGTTTCATACACA & 109 \\
\hline TWIST1 & TCGGACAAGCTGAGCAAGATT & GACCGAGAAGGCGTAGCTGA & 150 \\
\hline GLI2 & GTGGCCTACCAGCAGATTCT & GGGGTGGTGTGTGTCCAAA & 67 \\
\hline GAPDH & ACATCATCCCTGCCTCTACTC & CCTGCTTCACCACCTTCTTG & 180 \\
\hline
\end{tabular}
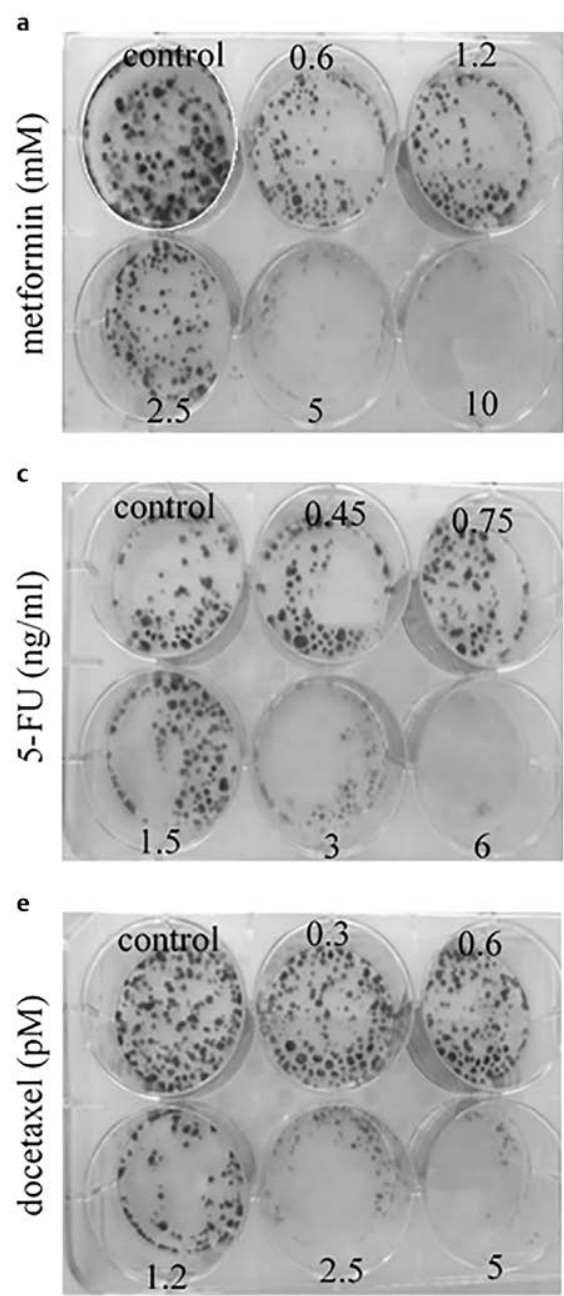

b

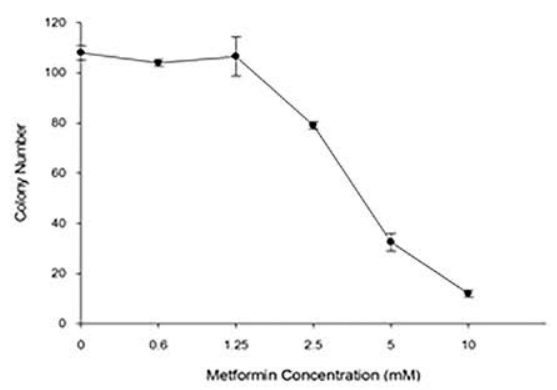

d

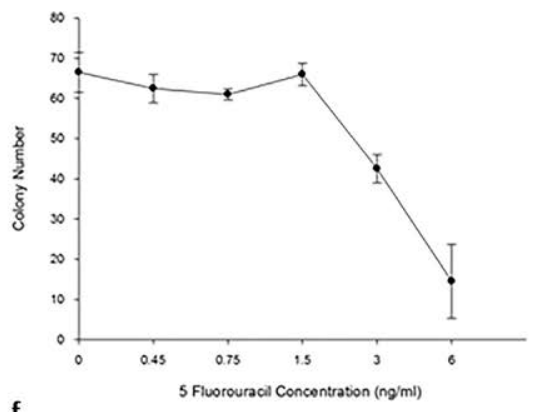

$\mathbf{f}$

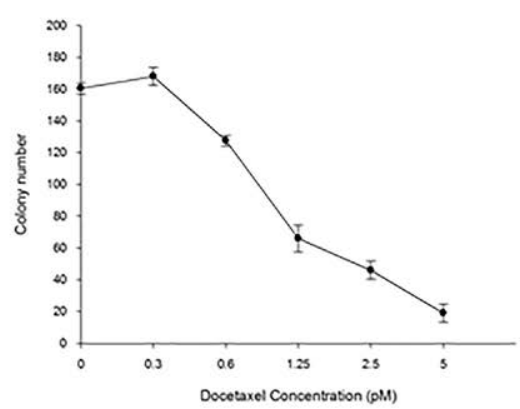

Fig. 1 The colony-forming ability of the cell was investigated by clonogenic assay to evaluate the cytotoxicity of metformin, 5-FU, docetaxel, and their combination effects. The cells treated with various concentrations of metformin a, 5-FU c, and docetaxel $\mathbf{c}$. The concentration-dependent cytotoxicity induced by drugs in AGS cells at 10 days $(\mathbf{b}, \mathbf{d}$, and $\mathbf{f})$. Data are presented as mean \pm standard deviation $(n=3)$. 


\section{Results}

\section{Metformin combined with 5-FU and docetaxel diminishes colony formation ability of the gastric cancer cells}

In the present study, we evaluated whether treatment with the drugs alone and combination of metformin/5-FU or metformin/ docetaxel can affect the abilities of the cancer cells to form colonies. The results showed that metformin, 5-FU, and docetaxel alone were effective in the control of the colony formation, but the combination treatments were more effective to reduce the number of cancer colonies when compared with 5-FU and docetaxel alone ( Fig. 1). As shown in $\triangleright$ Fig. 2, a combination of $2.5 \mathrm{mM}$ metformin and $1.5-6 \mathrm{ng} / \mathrm{ml} 5$-FU diminished the cell colony formation abil-

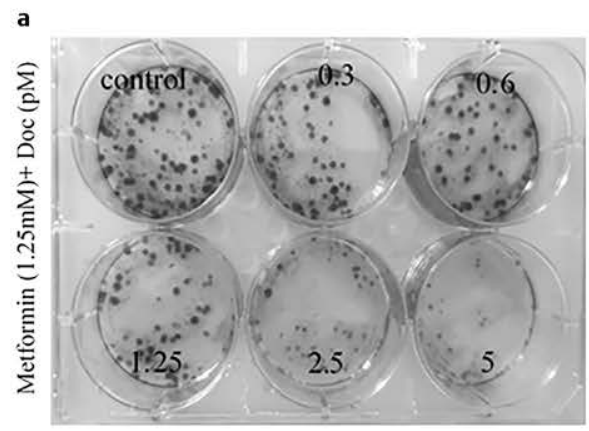

b
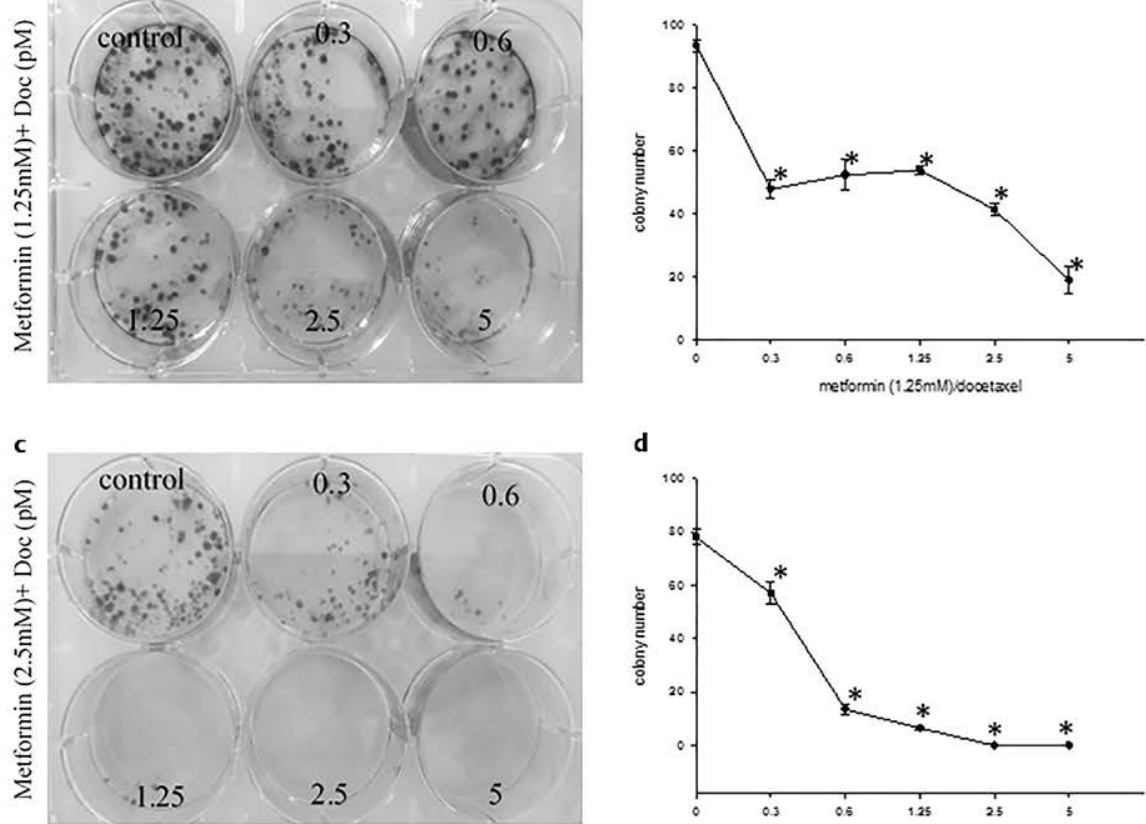

d
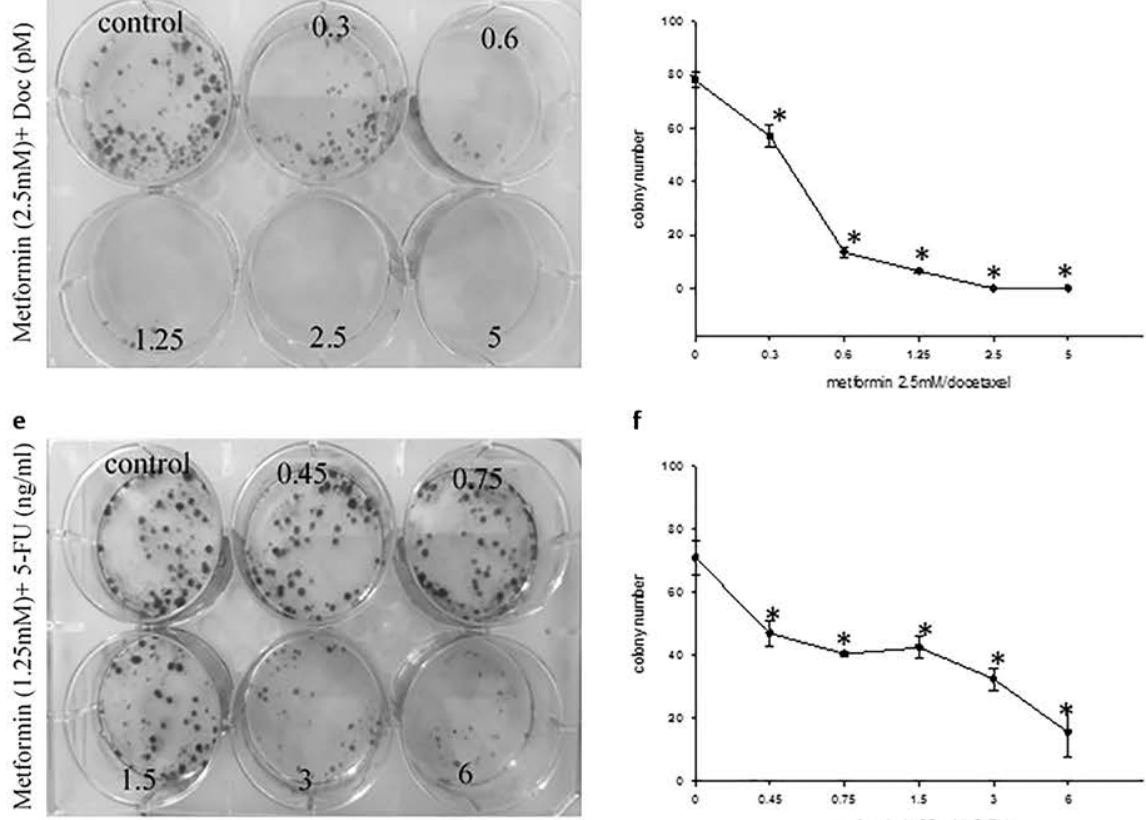

f
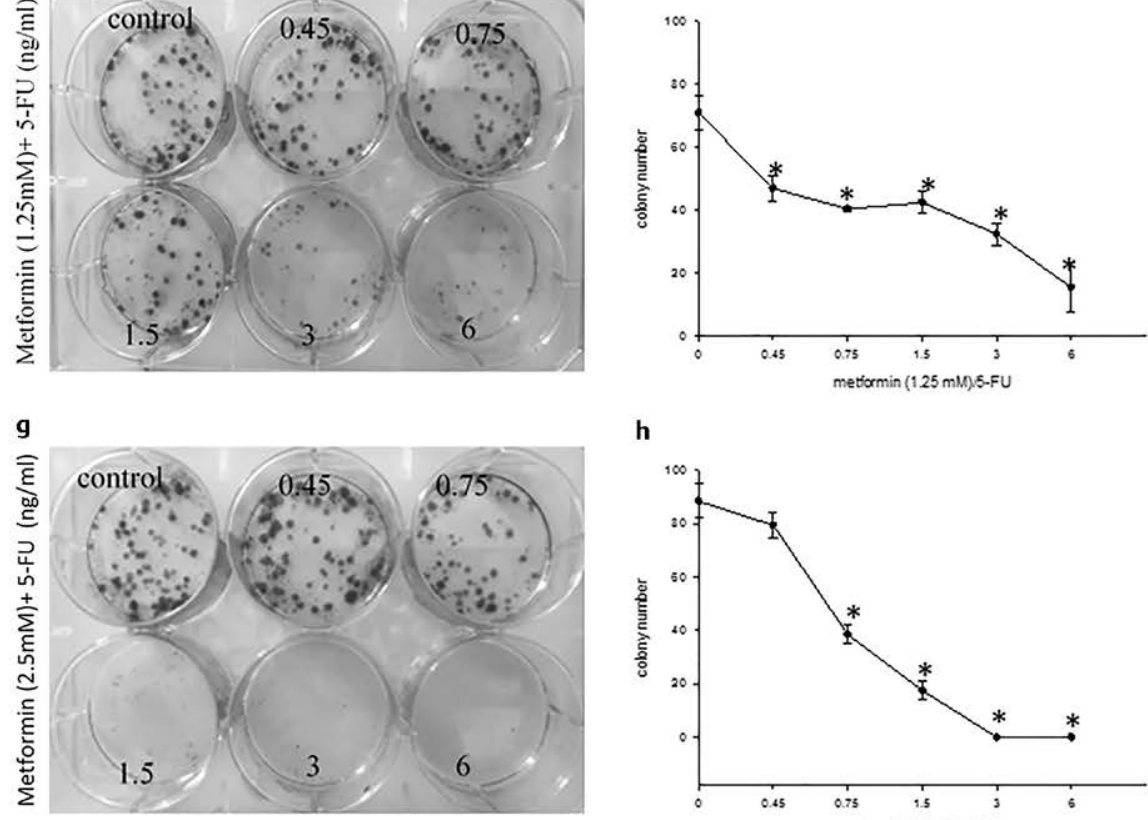

h

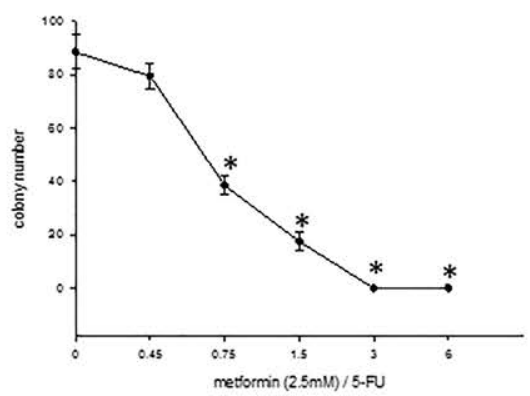

Fig. 2 The cells pretreated with two different concentrations of metformin ( 1.25 and $2.5 \mathrm{mM}$ ), then treated with various concentrations of docetaxel $(0.3-5 \mathrm{pM})$ and $5-\mathrm{FU}(0.45-6 \mathrm{ng} / \mathrm{ml})$. The concentration-dependent decrease in colony number was seen after 10 days of treatment with metformin/docetaxel and metformin/5-FU (a-h). Data are presented as mean \pm standard deviation $(n=3)$. 
ity. Furthermore, simultaneous treatment with $2.5 \mathrm{mM}$ metformin and 0.6-5 pM docetaxel significantly inhibited colony formation.

\section{Metformin increase sensitivity of gastric cancer cells to 5-FU and docetaxel}

Gastric cancer cells were pretreated with $5 \mathrm{mM}$ metformin and then treated with a subtoxic concentration of $5-\mathrm{FU}(0.2 \mu \mathrm{g} / \mathrm{ml})$ and docetaxel $(5 \mathrm{nM})$. The apoptosis was measured using the DAPi staining. Docetaxel alone and 5-FU alone increased significantly apoptosis, but low dose $(5 \mathrm{mM})$ metformin did not increased the apoptosis of gastric cancer cells compared to control $(P=0.358)$.

Metformin was found to significantly increase the 5 -FU and docetaxel sensitivity of AGS gastric cancer cells. The combination of metformin and 5-FU or docetaxel significantly increased apoptotic cells compared to each drug alone $(P=0.00)$ ( $>$ Fig. 3 ).

\section{Shh protein-expressing cells decrease after treatment with chemotherapy drugs in combination with metformin}

Next, we tried to examine the expression of Shh protein after treatment with different concentrations of metformin, 5-FU, docetaxel, and their combination in the gastric cancer cells. The results of this study showed that metformin, 5-FU, and docetaxel significantly reduced the number of cells expressing Shh compared to the control group.

As shown in > Fig. 4, the combination of $20 \mathrm{mM}$ metformin with 5-FU significantly reduced the number of cells expressing the Shh protein compared to the 5-FU alone. Furthermore, a combination of $20 \mathrm{mM}$ metformin with docetaxel was more effective in reducing cells expressing this protein than docetaxel alone ( $\triangleright$ Fig. 4).

\section{Efficacy of metformin/docetaxel versus metformin/ 5-FU on the expression of Gli1, Gli2, and Twist1 mRNA in the gastric cancer}

To evaluate the inhibitory role of the combination of metformin with 5-FU or docetaxel on the expression of Gli1, Gli2, and TWIST1 in gastric cancer, we pretreated the cells with $5 \mathrm{mM}$ metformin for $24 \mathrm{~h}$, then the cells treated with a sub-toxic concentration of 5-FU or docetaxel. Treatment with metformin alone and 5-FU alone decreased the expression of the Gli1, Gli2, and TWIST1 mRNA levels compared to control, but docetaxel only down-regulated the expression of Gli1 mRNA. Interestingly, we showed that metformin/ docetaxel combination significantly down-regulated the mRNA levels of Gli1, Gli2, and TWIST1 in the AGS gastric cancer cells compared
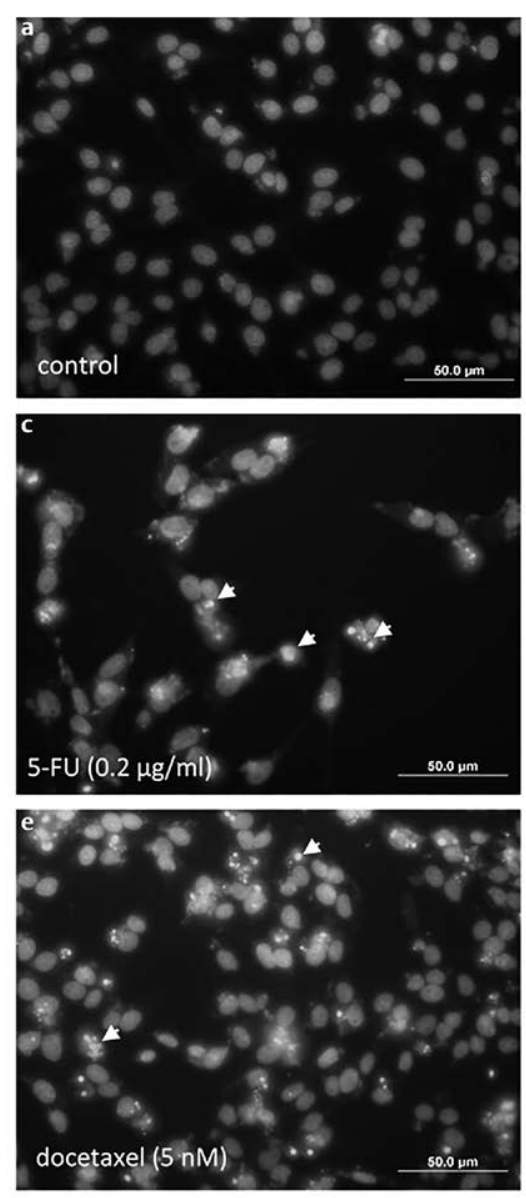
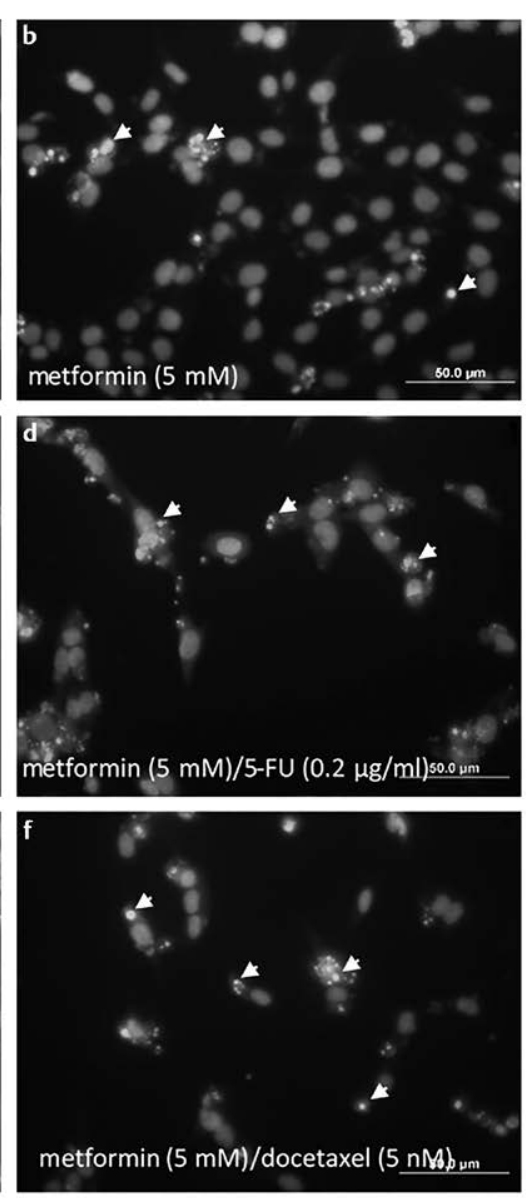

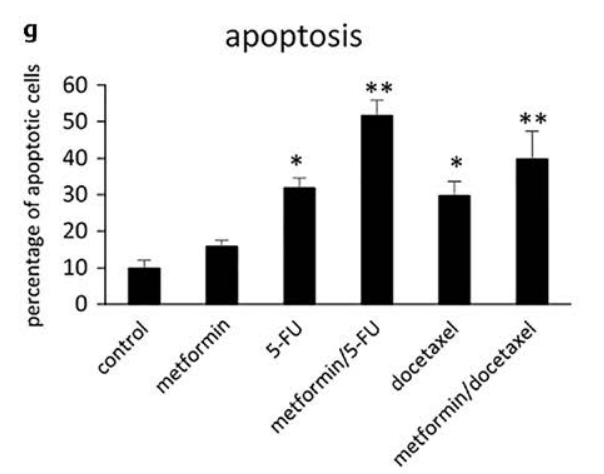

- Fig. 3 DAPi staining of AGS gastric cells treated with metformin, docetaxel, 5-FU, and their combinations. More apoptotic bodies (arrows) were seen after the combination of treatments $(\mathbf{a}-\mathbf{g}) .{ }^{*} p<0.05$ compared to control. ${ }^{*}{ }^{*} p<0.05$ compared to 5 -FU or docetaxel. 

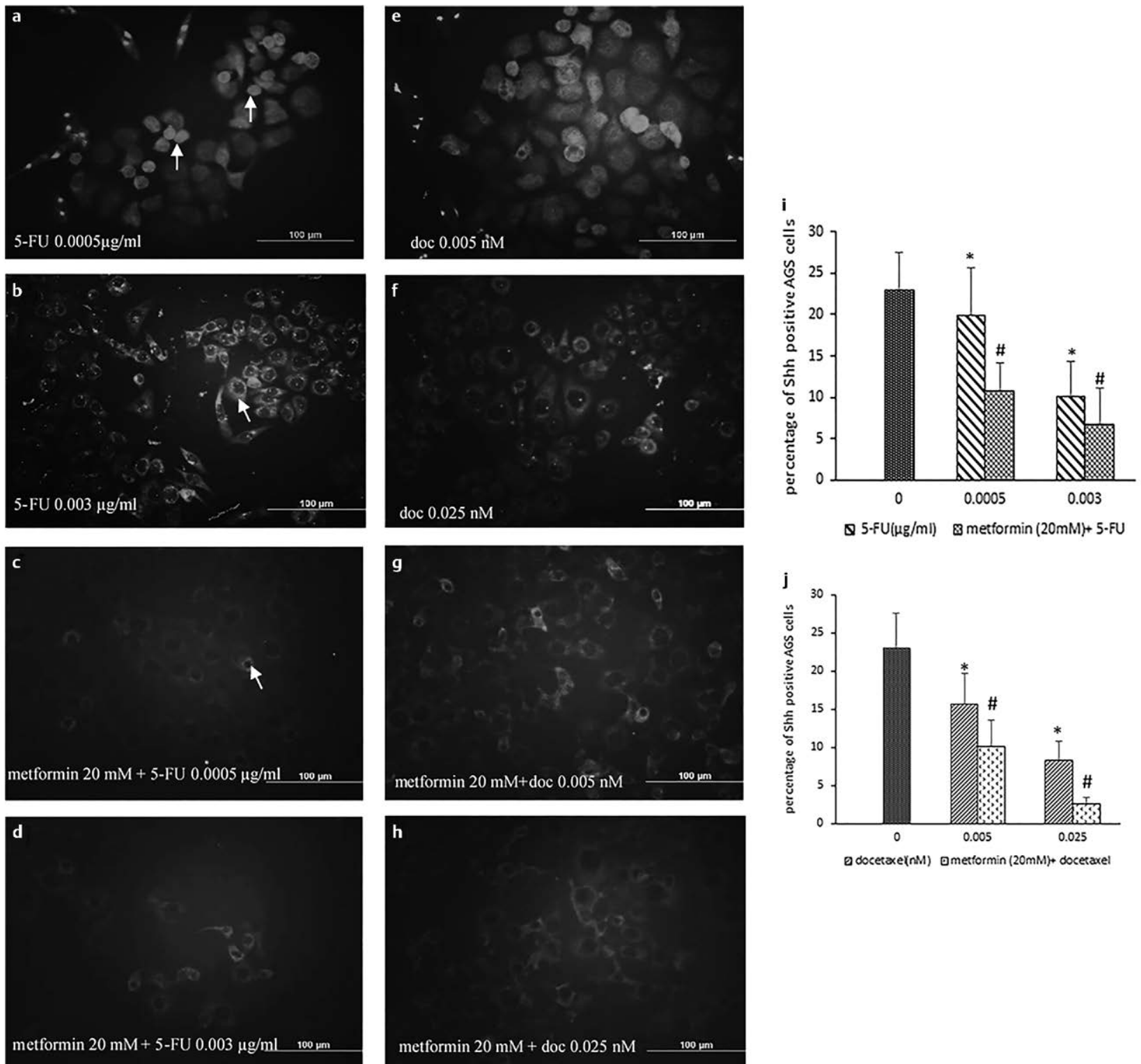

-Fig. 4 The combination of metformin with 5-FU and docetaxel inhibits Shh protein expression. The gastric cancer cells pretreated with $20 \mathrm{mM}$ metformin for $24 \mathrm{~h}$, then post-treated with various concentrations of $5-\mathrm{FU}(0.0005-0.0125 \mu \mathrm{g} / \mathrm{ml})$ and docetaxel $(\mathrm{doc})(0.005-1 \mathrm{nM})$ for $48 \mathrm{~h}$. The Shh positive cells were shown by white arrows. The quantitative data were presented in $\mathrm{j}$ and $\mathrm{i}$. The data are presented as mean \pm SEM, $\mathrm{n}=3$. ${ }^{*} P<0.05$ compared with the control group. ${ }^{\#} P<0.05$ compared with the 5 -FU and docetaxel treated group.

to docetaxel alone. In contrast, we found that metformin pretreatment combined with 5-FU did not significantly decrease the expression of the Gli1, Gli2, and TWIST1 compared to 5-FU alone (•Fig. 5).

\section{Discussion}

Docetaxel and 5-FU which induce DNA damages and apoptosis, are the first-line chemotherapy for gastric cancer. Unfortunately, most of patients with gastric cancer who are prescribed docetaxel or 5-FU show relapse and develop chemoresistance [16]. Metformin, an antidiabetic-drug, inhibits cancer proliferation through activation of AMPK pathway [17]. However, whether metformin can enhance effectiveness of 5-FU or docetaxel in gastric cancer is not clear. Since the Shh signaling promotes tumorigenesis and involved in multidrug resistance [18], ligand-dependent activation of Shh signaling has been demonstrated in gastrointestinal adenocarcinomas [19]. Previous studies demonstrated that inhibition of Shh/Gli1 pathway is a possible candidate for the treatment of many cancers $[20,21]$. Clearly, metformin can efficiently suppress the Shh signaling pathway in gastric cancer [22]. In the present study, we investigated the combination of metformin with chemotherapeutic agents as a more effective anticancer therapy in gastric cancer, particularly for 


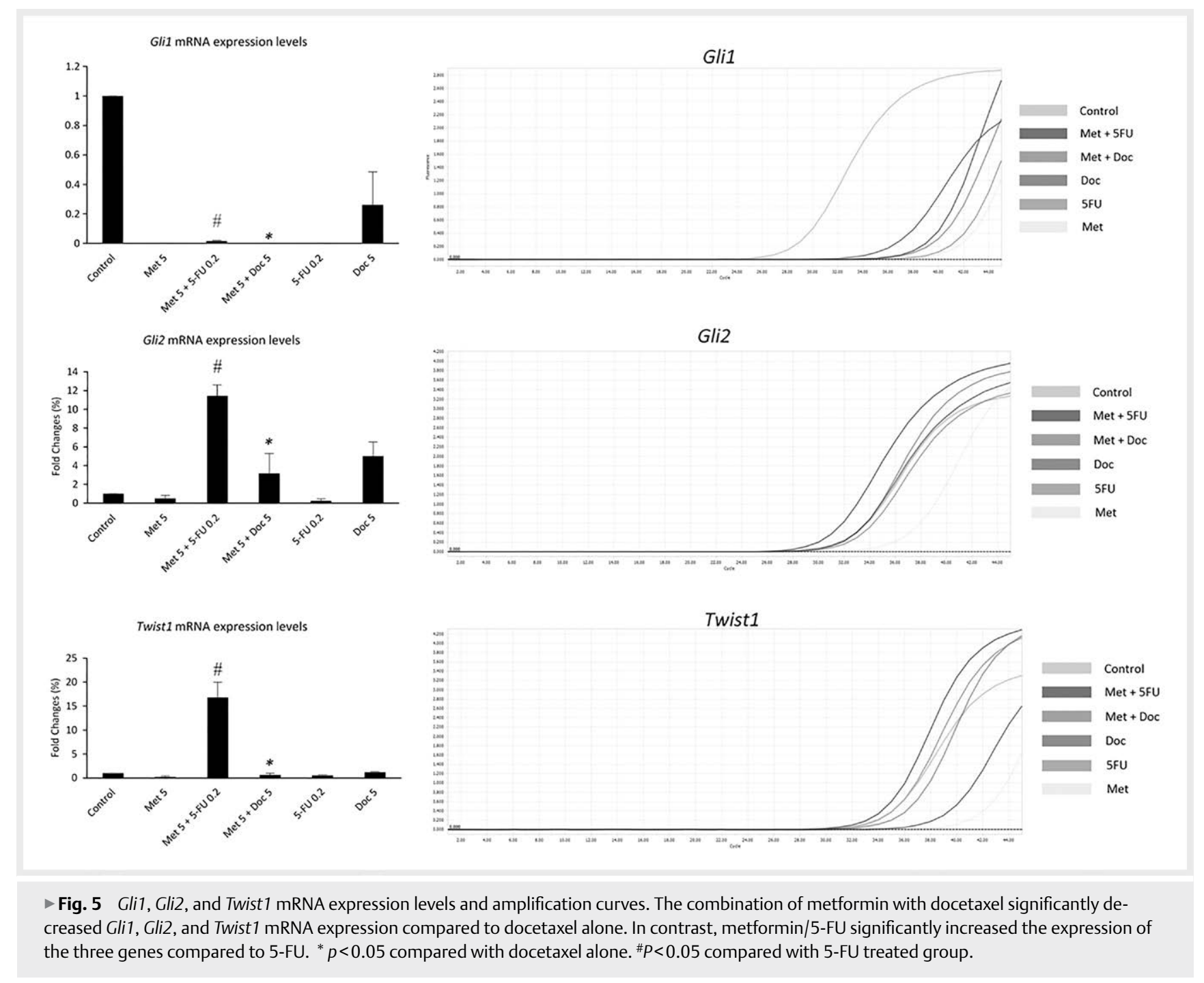

targeting the Shh/Gli1 signaling pathway. In our present study, the colony formation test demonstrated that the cell viability of AGS cell line decreased significantly after co-treated with low doses of metformin and the chemotherapeutics in comparison to monotherapy. In this study, we found that metformin alone decreased Gli1, Gli2, and TWIST1 mRNA expression levels in the gastric cancer cells. We also demonstrated that the expression of the Shh downstream genes, Gli1, Gli2, and Twist1 decreased after treatment with metformin/docetaxel, but its expression did not change after metformin/5-FU treatment. Additionally, we found that Shh protein expression decreased in the combination treatment groups indicating synergistic suppression of Shh pathway.

Similar to our study, Song et al. demonstrated that metformin can decrease Shh, Gli1, Gli2, and SMO expression in two gastric cancer cell lines [22]. Also, Fan et al. showed that metformin by downregulating the Shh signaling pathway could inhibit the proliferation of breast cancer cells both in vitro and in vivo [17]. Similar to our study, Gonnissen et al. showed that the combination of metformin and GANT61 inhibit the proliferation and enhanced radiosensitivity of the prostatic cancer cells [23]. In a study by Yu et al. results showed that metformin enhances cisplatin or rapamycin cytotoxicity in gastric cancer through activation of AMPK and suppression of the mTOR pathway [24]. Wandee et al. studied the chemosensitizing effects of metformin in the cholangiocarcinoma cells. They showed that metformin not only enhanced antiproliferative characteristics of cisplatin but also conferred anti-metastatic effects in the cholangiocarcinoma cells. This chemosensitizing effect was related to the activation of the AMPK pathway and suppression of Akt, mTOR, and p70S6K [25]. Guimaraes et al. studied the chemosensitizing effects of metformin on cisplatin-resistant and paclitaxel-resistant ovarian cancer cell lines. They showed that metformin enhanced the sensitivity of cancerous cells to these drugs by reducing the mRNA expression of the NF-kB signaling pathway in the ovarian cancer cells [26].

Also, several studies showed that metformin in combination with chemotherapeutic agents can promote the efficacy of the agents against many cancers via different molecular mechanisms [27]. Zhang et al. showed synergistic cytotoxic effects of metformin in combination with 5-FU in the CD133 + SW620 cells [28]. Metformin combined with arsenic trioxide was more effective to inhib- 
it hepatocellular carcinoma cell growth through attenuating expression of $\mathrm{Bcl}-2$ [29]. The combined use of metformin with rapamycin had more cytotoxic effects on breast cancer cells through PI3K/AKT/mTOR pathways [30].

Despite this, several studies showed that metformin does not have a chemosensitizing effect on chemotherapeutics or even antagonize their effect to kill cancerous cells. In a retrospective cohort study, Mayer et al. showed that metformin use with docetaxel did not improve the overall survival of the patients and metformin may not be an effective chemosensitizer for castration-resistant prostate cancer. Despite this fact, this study couldn't rule out metformin as a chemosensitizer for docetaxel chemotherapy completely [31]. In another study, Lesan et al. demonstrate the antagonistic effects of metformin with cisplatin in the MKN-45 gastric cancer cell line [32]. Zhou et al. showed that the metformin has an antagonistic effect on 5-FU in larynx carcinoma Hep-2 cells through signaling pathways of AMPK- $\alpha$, P21, and Cyclin D1 [33].

Gli1/Gli2 activation promotes invasion and metastasis [34]. Overexpression of Gli1 is very common in gastric cancers [35]. In gastric cancer, the deregulated Shh pathway with activation of Gli transcription factors enhances the migration and metastasis as well as induces drug resistance. Yao et al. suggested that coexpression of Gli1 and p-AKT in gastric cancer associated with invasion and drug resistance [36]. In another study, Yu et al. showed that genistein inhibits gastric cancer stem cell proliferation by reducing Gli1 and CD44 mRNA and protein expression levels [37].

\section{Conclusion}

In conclusion, our findings confirm that the combination of metformin with 5-FU or docetaxel could synergistically inhibit the proliferation of gastric cancer. The inhibitory effects of metformin/5Fu and metformin/docetaxel may be associated with suppression of Shh/Gli1 pathway. So, the combination of metformin with the chemotherapeutics may be a highly efficient treatment for gastric cancer patients.

\section{Author's Contributions}

NN took responsibility for design of the study, data acquisition, statistical analysis and wrote the paper; MFA, MAV and RP participated in the data acquisition and drafted the manuscript; FJ made substantial contributions to the conception or design of the work and English edit. All authors read and approved the final manuscript.

\section{Funding}

This work was supported by a thesis grant for M.Sc. (IR.ARUMS. REC.1397.240) and a medical student research grant (IR.ARUMS. REC.1398.418) from Ardabil University of Medical Sciences.

\section{Acknowledgements}

The authors gratefully acknowledge the use of the services and facilities of the Ardabil University of Medical Sciences.
Conflict of Interest

The authors declare that the research was conducted in the absence of any commercial or financial relationships that could be construed as a potential conflict of interest. All authors declare that they have no conflict of interest.

References

[1] Etemadi A, Safiri S, Sepanlou SG et al. The global, regional, and national burden of stomach cancer in 195 countries, 1990-2017: A systematic analysis for the Global Burden of Disease study 2017. Lancet Gastroenterol Hepatol 2020; 5: 42-54

[2] Rawla P, Barsouk A. Epidemiology of gastric cancer: Global trends, risk factors and prevention. Prz Gastroenterol 2019; 14: 26

[3] Bilici A. Treatment options in patients with metastatic gastric cancer: Current status and future perspectives. World J Gastroenterol 2014; 20: 3905

[4] Buckland G, Travier N, Huerta J et al. Healthy lifestyle index and risk of gastric adenocarcinoma in the EPIC cohort study. Int J Cancer 2015; 137: 598-606

[5] de Weger VA, Beijnen JH, Schellens JH. Cellular and clinical pharmacology of the taxanes docetaxel and paclitaxel-a review. Anti-cancer drugs 2014; 25: 488-494

[6] Kim R, Ohi Y, Inoue $\mathrm{H}$ et al. Taxotere activates transcription factor AP-1 in association with apoptotic cell death in gastric cancer cell lines. Anticancer res 1999; 19: 5399-5405

[7] Kim NK, Park YS, Heo DS et al. A phase III randomized study of 5-fluorouracil and cisplatin versus 5-fluorouracil, doxorubicin, and mitomycin $\mathrm{C}$ versus 5 -fluorouracil alone in the treatment of advanced gastric cancer. Cancer 1993; 71: 3813-3818

[8] Rena G, Hardie DG, Pearson ER. The mechanisms of action of metformin. Diabetologia 2017; 60: 1577-1585

[9] Kasznicki ], Sliwinska A, Drzewoski ]. Metformin in cancer prevention and therapy. Ann Trans Med 2014; $2: 57$

[10] Honjo S, Ajani JA, Scott AW et al. Metformin sensitizes chemotherapy by targeting cancer stem cells and the mTOR pathway in esophageal cancer. Int J Oncol 2014; 45: 567-574

[11] Liu X, Yun F, Shi L et al. Roles of signaling pathways in the epithelialmesenchymal transition in cancer. Asian Pac J Cancer Prev 2015; 16: 6201-6206

[12] Huang L, Wu R-L, Xu A-M. Epithelial-mesenchymal transition in gastric cancer. Am J Transl Res 2015; 7: 2141

[13] Hsu K-W, Hsieh R-H, Huang K-H et al. Activation of the Notch1/STAT3/ Twist signaling axis promotes gastric cancer progression. Carcinogenesis 2012; 33: 1459-1467

[14] Fatehi Aghdam M, Najafzadeh NMGG. Evaluation of cytotoxic effects of the combination of metformin with docetaxel and 5-fluorouracil on the gastric cancer cells. Journal of Isfahan Medical School 2020; 38: 139-146

[15] Mohammadi Jobani B, Najafzadeh N, Mazani M et al. Molecular mechanism and cytotoxicity of allicin and all-trans retinoic acid against CD44 + versus CD117 + melanoma cells. Phytomedicine 2018; 48: 161-169

[16] Rosenberg AJ, Rademaker A, Hochster HS et al. Docetaxel, Oxaliplatin, and 5-Fluorouracil (DOF) in Metastatic and Unresectable Gastric/ Gastroesophageal Junction Adenocarcinoma: A Phase II Study with Long-Term Follow-Up. The oncologist 2019; 24: 1039 
[17] Fan C, Wang Y, Liu Z et al. Metformin exerts anticancer effects through the inhibition of the Sonic hedgehog signaling pathway in breast cancer. Int J Mol Med 2015; 36: 204-214

[18] Islam S, Mokhtari R, Noman A et al. Sonic hedgehog (Shh) signaling promotes tumorigenicity and stemness via activation of epithelial-tomesenchymal transition (EMT) in bladder cancer. Mol Carcinog 2016; 55: 537-551

[19] Lees C, Howie S, Sartor RB et al. The hedgehog signalling pathway in the gastrointestinal tract: Implications for development, homeostasis, and disease. Gastroenterology 2005; 129: 1696-1710

[20] Sanchez P, Hernández AM, Stecca B et al. Inhibition of prostate cancer proliferation by interference with SONIC HEDGEHOG-GLI1 signaling. Proc Natl Acad Sci USA 2004; 101: 12561-12566

[21] Shahi MH, Rey JA, Castresana JS. The sonic hedgehog-GLI1 signaling pathway in brain tumor development. Expert Opin Ther Targets 2012; 16: $1227-1238$

[22] Song Z, Wei B, Lu C et al. Metformin suppresses the expression of Sonic hedgehog in gastric cancer cells. Mol Med Rep 2017; 15 : 1909-1915

[23] Gonnissen A, Isebaert S, McKee CM et al. The effect of metformin and GANT61 combinations on the radiosensitivity of prostate cancer cells. Int J Mol Sci 2017; 18: 399

[24] Yu Y, Fang W, Xia T et al. Metformin potentiates rapamycin and cisplatin in gastric cancer in mice. Oncotarget 2015; 6: 12748

[25] Wandee J, Prawan A, Senggunprai L et al. Metformin sensitizes cholangiocarcinoma cell to cisplatin-induced cytotoxicity through oxidative stress mediated mitochondrial pathway. Life Sci 2019; 217: 155-163

[26] dos Santos Guimarães I, Ladislau-Magescky T, Tessarollo NG et al. Chemosensitizing effects of metformin on cisplatin-and paclitaxelresistant ovarian cancer cell lines. Pharmacol Rep 2018; 70: 409-417

[27] Peng M, Darko KO, Tao T et al. Combination of metformin with chemotherapeutic drugs via different molecular mechanisms. Cancer Treat Rev 2017; 54: 24-33
[28] Zhang Y, Guan M, Zheng Z et al. Effects of metformin on CD133+ colorectal cancer cells in diabetic patients. PLoS One 2013; 8(11): e81264

[29] Yang X, Sun D, Tian Y et al. Metformin sensitizes hepatocellular carcinoma to arsenic trioxide-induced apoptosis by downregulating Bcl2 expression. Tumor Biol 2015; 36: 2957-2964

[30] Zakikhani M, Blouin M-J, Piura E et al. Metformin and rapamycin have distinct effects on the AKT pathway and proliferation in breast cancer cells. Breast Cancer Res Treat 2010; 123: 271-279

[31] Mayer M], Klotz LH, Venkateswaran V. The effect of metformin use during docetaxel chemotherapy on prostate cancer specific and overall survival of diabetic patients with castration resistant prostate cancer. J Urol 2017; 197: 1068-1075

[32] Lesan V, Ghaffari SH, Salaramoli J et al. Evaluation of antagonistic effects of metformin with Cisplatin in gastric cancer cells. Int J Hematol Oncol Stem Cell Res 2014; 8: 12

[33] Zhou C, Li X, Shan S et al. Metformin's effect on 5-fluorouracil, cisplatin, paclitaxel in laryngocarcinoma Hep-2 cells. J Otorhinolaryngol Head Neck Surg 2017; 31: 524-528

[34] Lu J-t, He W, Wei W. Hedgehog signaling pathway mediates invasion and metastasis of hepatocellular carcinoma via ERK pathway. Acta Pharmacol Sin 2012; 33: 691-700

[35] Ma X, Chen K, Huang $S$ et al. Frequent activation of the hedgehog pathway in advanced gastric adenocarcinomas. Carcinogenesis 2005; 26: $1698-1705$

[36] Yao Y, Zhou D, Shi D et al. GLI1 overexpression promotes gastric cancer cell proliferation and migration and induces drug resistance by combining with the AKT-mTOR pathway. Biomed Pharmacother 2019; 111: 993-1004

[37] Yu D, Shin H-S, Lee YS et al. Genistein attenuates cancer stem cell characteristics in gastric cancer through the downregulation of Gli1. Oncol Rep 2014; 31: 673-678 